\title{
CRISPR-Cas9-mediated Large Cluster Deletion and Multiplex Genome Editing in Paenibacillus polymyxa
}

\author{
Meliawati Meliawati, ${ }^{1}$ Christa Teckentrup, ${ }^{1}$ and Jochen Schmid ${ }^{1 \star}$
}

${ }^{1}$ Institute of Molecular Microbiology and Biotechnology, University of Münster, Corrensstrasse 3, 48149 Münster, Germany

\begin{abstract}
The use of molecular tools based on the clustered regularly interspaced short palindromic repeats-Cas (CRISPR-Cas) systems has rapidly advanced genetic engineering. These molecular biological tools have been applied for different genetic engineering purposes in multiple organisms, including the quite rarely explored Paenibacillus polymyxa. However, only limited studies on large cluster deletion and multiplex genome editing have been described for this highly interesting and versatile bacterium. Here, we demonstrate the utilization of a Cas9based system to realize targeted deletions of four biosynthetic gene clusters in the range of $12 \mathrm{~kb}$ to $41 \mathrm{~kb}$ by the use of a single targeting sgRNA. Furthermore, we also harness the system for multiplex editing of genes and large genomic regions. Multiplex deletion was achieved with more than $80 \%$ efficiency, while simultaneous integration at two distantly located sites was obtained with $58 \%$ efficiency. The findings reported in this study are anticipated to accelerate future research in P. polymyxa and related species.
\end{abstract}

Keywords: CRISPR, Cas9, multiplexing, Paenibacillus polymyxa, genetic engineering, biosynthetic gene cluster, single sgRNA 


\section{Introduction}

Paenibacillus polymyxa is a Gram-positive, facultative anaerobe, endospore forming, nonpathogenic soil bacterium. It is known for its nitrogen fixation capability which makes it attractive for utilization in modern agriculture. Furthermore, $P$. polymyxa naturally produces a wide range of valuable compounds such as exopolysaccharides (EPS), 2,3-butanediol, as well as antibiotics and antimicrobial peptides. ${ }^{1} P$. polymyxa produces different types of EPS depending on the carbon source. These EPSs have unique characteristics and physiochemical properties which could be explored for different applications, such as cosmetics, coatings or within the agrochemical industry. ${ }^{2}$ As $P$. polymyxa gains more and more interests as biotechnological workhorse, the availability of stable and robust genetic tools is essential to further study and engineer the strain towards a versatile platform organism. ${ }^{3}$ While some molecular biology tools have been described for Paenibacillus species in the past, ${ }^{4-6}$ the efficiencies were quite low and further development is of highest interest.

The discovery of clustered regularly interspaced short palindromic repeats (CRISPR) has revolutionized biotechnology research in unprecedented ways. As an RNA-guided adaptive defense mechanism, CRISPR originates and naturally exists in many bacteria and archaea. ${ }^{7}$ Today, the basic mechanism has widely been adapted in different research fields and applied for genetic engineering of various organisms. Several CRISPR-associated (Cas) proteins have been described, but Cas9 is the most studied and well-characterized thus far. Cas9 belongs to the class 2 type II CRISPR-Cas system and has a single large effector protein. ${ }^{8}$ To realize a functional CRISPR-Cas9 system, the expression of Cas9 needs to be accompanied by guide RNA (gRNA) which consists of a CRISPR-RNA (crRNA) and trans-activating crRNA (tracrRNA) complex containing a spacer sequence homologous to the targeted region. A shorter and synthetic crRNA-tracrRNA, called single guide RNA (sgRNA), is commonly used today. The sgRNA acts as a guide for Cas9 to the targeted sequence. Cas9 itself is an endonuclease which recognizes the corresponding protospacer adjacent motive (PAM) sequence of 5'-NGG located downstream of the spacer. Upon binding to the target region, 
bioRxiv preprint doi: https:/doi.org/10.1101/2021.08 .06.455192; this version posted November 8 2021. The copyright holder for this preprint (which was not certified by peer review) is the author/funder, who has granted bioRxiv a license to display the preprint in perpetuity. It is made available under aCC-BY-NC-ND 4.0 International license.

Cas9 is activated and generates a double strand DNA (dsDNA) break. This dsDNA break triggers the native DNA repair system which, depending on the organism, could be realized by homology-directed repair (HDR), non-homologous end joining, or alternative end-joining repair mechanisms. ${ }^{9-11}$ Further Cas proteins, such as Cas12a are also used in biotechnology research today and many variants such as nicking or deactivated Cas proteins exist. ${ }^{12,13}$ Thus, CRISPR-Cas systems can be used for genome editing, gene regulation as well as targeted labelling. This high versatility of CRISPR-Cas renders it a very powerful tool of modern biotechnology.

In 2017, the implementation of a CRISPR-based system to facilitate efficient genome editing in $P$. polymyxa was reported for the first time. ${ }^{14}$ The single-vector-based system was used to mediate single-gene deletions as well as the deletion of a genomic region of $18 \mathrm{~kb}$ by utilizing two targeting sgRNAs. Furthermore, a system for single and multiple gene regulation has been developed by employing the DNase-inactive variant of an optimized Cas12a (dCas12a) from Acidaminococcus $s p .{ }^{13} \mathrm{In}$ addition, Kim et al. ${ }^{15}$ have recently developed a multiplex base editing tool for P. polymyxa by fusing the dCas9 with a cytidine deaminase to mediate $\mathrm{C}$ to $\mathrm{T}$ substitutions. However, no studies have reported multiplex gene deletions or integrations in P. polymyxa thus far. As modification of various genes is often needed for efficient metabolic engineering or the development of chassis organisms, the possibility to perform targeted multiple gene editing is highly attractive. In this study, we scope on the exploitation of multiplex genome editing to realize simultaneous gene deletions and integrations in $P$. polymyxa. The genes and cluster which are essential for the EPS production were selected as initial targets to allow for eased screening. In addition, we demonstrate the functionality of a single sgRNAguided CRISPR-Cas9 approach to facilitate large cluster deletions, which will be important to realize mutant strains with minimized genomes towards the development of a robust and versatile chassis organism. 


\section{Results and Discussion}

Multiple genetic modifications are often required for microbial strain engineering. These modifications include, for example, gene deletions or integrations to direct the metabolism towards the desired pathway. Furthermore, deletion of non-essential genomic regions is of interest to generate minimalistic strains with superior performance. ${ }^{16,17}$ The availability of genetic tools which could facilitate reliable genome editing for such purposes is essential. While CRISPR-Cas-based systems have been used for genetic engineering of $P$. polymyxa, only limited studies reported their applications beyond the single-gene level. Here, we report the utilization of a Cas9-based system to realize deletion of large genomic regions as well as multiplex genome editing. The pCasPP plasmid was used as a base to realize the different genomic modifications. ${ }^{14}$ In brief, this plasmid contains the cas9 gene from Streptococcus pyogenes which is codon-optimized for expression in Streptomyces. The expression of Cas9 is under the control of the constitutive sgsE promoter from Geobacillus stearothermophilus while the expression of the sgRNA is controlled by the constitutive gapdh promoter from Eggerthella lenta. ${ }^{18,19}$ Homologous regions of $\sim 1 \mathrm{~kb}$ upstream and downstream of the targeted regions were provided as HDR template. The spacer sequence was chosen 20-nt upstream of the NGG PAM sites.

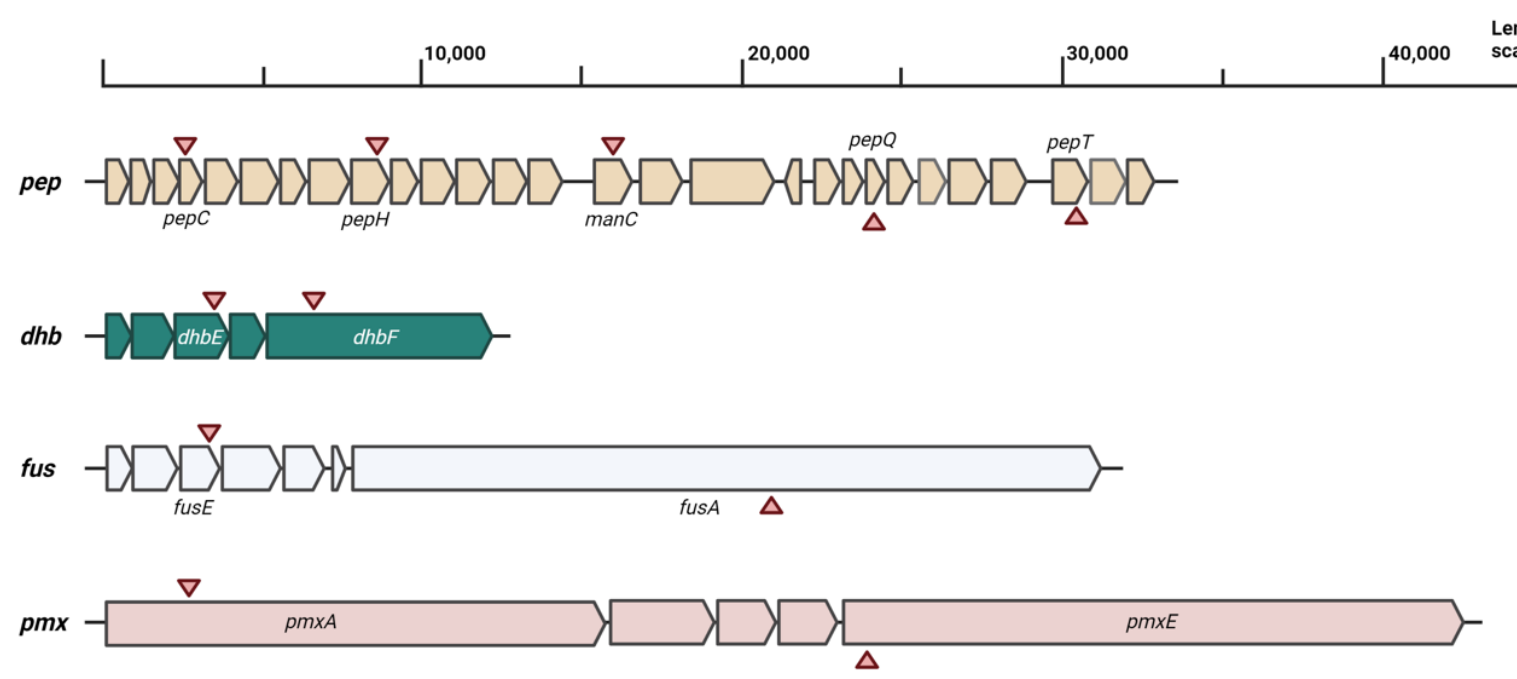

Figure 1. Schematic overview of the biosynthetic gene clusters of paenan (pep), bacillibactin (dhb), fusaricidin (fus), and polymyxin ( $p m x$ ) of $P$. polymyxa DSM 365. The positions which were chosen as cutting sites within the respective genes are indicated by triangles. 
bioRxiv preprint doi: https://doi.org/10.1101/2021.08 06.455192; this version posted November 8, 2021. The copyright holder for this preprint (which was not certified by peer review) is the author/funder, who has granted bioRxiv a license to display the preprint in perpetuity. It is made available under aCC-BY-NC-ND 4.0 International license.

In this study, we demonstrate the targeted deletions of four biosynthetic gene clusters (BGCs) which are responsible for the biosynthesis of paenan (pep), bacillibactin ( $d h b)$, fusaricidin (fus), and polymyxin $(p m x)$ (Figure 1). To realize the cluster deletion, we employed the pCasPPbased plasmid only equipped with one targeting sgRNA. To analyze its efficiency, we first investigated the pep cluster which is $32.8 \mathrm{~kb}$ in size and comprises of 28 genes which support the production of paenan, the glucose-derived EPS produced by $P$. polymyxa. Deletion of the pep cluster will lead to elimination of paenan biosynthesis and therefore the mutants will not show a slimy phenotype when grown on EPS-inducing plates with glucose as the carbon source $\left(\right.$ EPS $\left._{\mathrm{glc}}\right)$. Five different positions in the pep cluster were individually targeted to evaluate whether there is an effect of the location of the dsDNA break in the region on the editing efficiency. They were distributed within the cluster and had different distances to the homologous regions provided as repair template. The targeted sites were located in the pepC (pep-sg1), pepH (pep-sg2), manC (pep-sg3), pepQ (pep-sg4), and pepT (pep-sg5) genes, respectively (Table 1). The sgRNAs were chosen so that pep-sg1/sg5 and pep-sg2/sg4 had similar distances to the homologous regions, but located at the opposite ends of the cluster. Meanwhile, pep-sg3 was located in the middle of the cluster. Colonies in which the pep cluster is successfully deleted should result in a $3 \mathrm{~kb}$ PCR fragment when screened with primers binding outside of the homologous regions (Figure 2B). No amplicon should be obtained by the applied PCR reaction conditions for the wild type strain in which the pep cluster is still intact. Except for the targeting of pep-sg1, each conjugation round resulted in around 10 to 60 exconjugants with conjugation efficiencies between $1 \times 10^{-6}$ to $4 \times 10^{-6}$. Screening of the exconjugants showed that four out of five sgRNAs tested resulted in the deletion of the pep cluster. As expected, no slimy appearance was observed for the mutants on EPS glc plate (Figure 2C). An editing efficiency of $90 \%$ was obtained when pep-sg2 was targeted, while it was $100 \%$ for pep-sg3, pep-sg4, and pep-sg5 (Figure 3A). Surprisingly, despite multiple trials, no exconjugants could be obtained when pep-sg1 was targeted. Thus, a tendency in which targeting the sites from the middle to $3^{\prime}$ end of pep cluster results in higher success rates to achieve the targeted deletion was observed. As pep-sg1 and pep-sg5 actually have similar 
bioRxiv preprint doi: https://doi org/10.1101/2021.08.06.455192; this version posted November 8,2021 . The copyright holder for this preprint (which was not certified by peer review) is the author/funder, who has granted bioRxiv a license to display the preprint in perpetuity. It is made available under aCC-BY-NC-ND 4.0 International license.

distances to the homologous regions, the results suggest that distance of the cutting site to the homologous regions is not the only factor which determines the success of HDR.

A

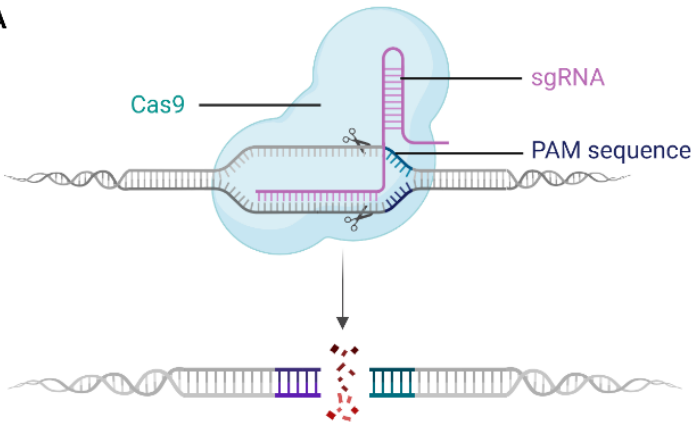

Double-stranded break

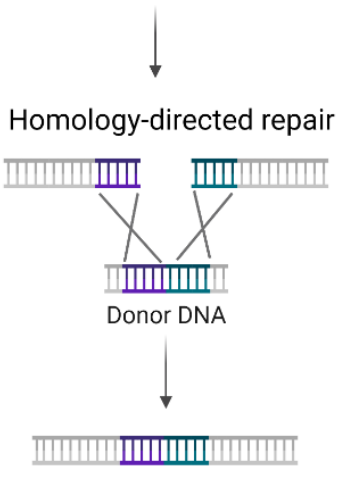

Repaired DNA
B

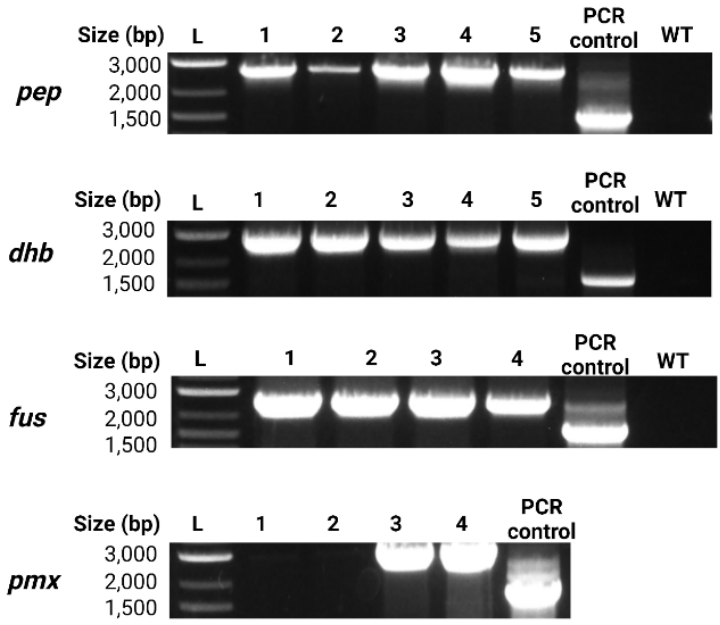

C

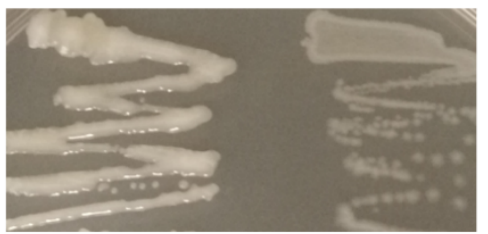

Figure 2. CRISPR-Cas9-mediated deletion of different biosynthetic gene clusters in P. polymyxa. (A) Schematic overview of Cas9-based targeted genome editing by employing the homology-directed repair mechanism. (B) Deletion of paenan (pep), fusaricidin (fus), bacillibactin $(d h b)$, and polymyxin ( $p m x)$ clusters. PCR screening of randomly picked exconjugants (1-5), wild type (WT), and a PCR control. The PCR control was included to confirm the viability of the colony PCR from the WT strain by amplification of the 16S rRNA gene. The DNA ladder used was $1 \mathrm{~kb}$ Plus DNA Ladder from NEB. (C) Growth of WT (left) and mutant strains (right) on EPS-inducing plate with glucose as the carbon source.

Subsequently, we targeted three other BGCs to see whether this phenomenon is also observed in other clusters or rather specific for the pep cluster. The clusters investigated were dhb (12 kb), fus (31 kb), and pmx (41 kb), which are responsible for the biosynthesis of bacillibactin, fusaricidin, and polymyxin, respectively. Two positions were individually targeted for each cluster, one located closer to the $5^{\prime}$ end (sg1) and one at the middle to $3^{\prime}$ end region (sg2) (Table 1). When targeting the $d h b$ cluster, there was no difference in regards to the editing efficiency. Screening of the exconjugants showed that $d h b$ deletion was achieved with $100 \%$ efficiency when $d h b$-sg1 or $d h b$-sg2 was targeted. Interestingly, for fus and $p m x$, we observed the similar phenomenon as for the pep cluster, in which the deletion was not 
bioRxiv preprint doi: https://doi org/10.1101/2021.08.06 455192; this version posted November 8,2021 . The copyright holder for this preprint (which was not certified by peer review) is the author/funder, who has granted bioRxiv a license to display the preprint in perpetuity. It is made available under aCC-BY-NC-ND 4.0 International license.

successful when fus-sg1 and pmx-sg1 were targeted. Meanwhile, it was possible to delete the cluster when targeting the sites located closer to the $3^{\prime}$ end (Figure $3 \mathrm{~B}$ ). In the case of fus cluster, the fus-sg2 is $20 \mathrm{~kb}$ and $10 \mathrm{~kb}$ away from the homologous regions, which is similar to pep-sg4 position targeted for the pep cluster deletion. By targeting fus-sg2, we successfully deleted the fus cluster with an average efficiency of $95 \%$. Meanwhile, deletion of pmx cluster was achieved with $39 \%$ efficiency when targeting the pmx-sg2. Although deletion of the relatively small $d h b$ cluster could be realized by targeting either $d h b$-sg1 or $d h b$-sg2, we observed that targeting larger clusters on the middle to $3^{\prime}$ end regions resulted in higher efficiencies. In fact, we were not able to achieve the deletion of pep, fus, and pmx clusters when targeting the sites located $\sim 2.5 \mathrm{~kb}$ away from the $5^{\prime}$ end (corresponding $\mathrm{sg} 1 \mathrm{~s}$ ). Our findings suggest that the position of the cutting site has a significant impact on the success rate of large BGCs deletion by the use of a single sgRNA. We hypothesize that the threedimensional structure of the BGCs might also be involved in this observation, but this requires further investigation. Based on these results, we thus recommend to target location in the middle to $3^{\prime}$ end regions when aiming for deletion of large BGCs, as it was proved to be successful for the deletion of four different BGCs investigated in this study.

Table 1. Overview of the biosynthetic gene clusters investigated in this study. Different positions in the clusters were targeted by individual sgRNA. The distance of each targeted site to the homologous regions are also listed.

\begin{tabular}{|c|c|c|c|c|c|c|}
\hline $\begin{array}{l}\text { Gene } \\
\text { cluster }\end{array}$ & Product & Size (kb) & $\begin{array}{l}\text { Targeted } \\
\text { site }\end{array}$ & $\begin{array}{l}\text { Targeted } \\
\text { gene }\end{array}$ & Predicted gene function & $\begin{array}{l}\text { Distance of targeted site } \\
\text { to homologous regions } \\
\text { (in kb, 5' end; 3' end) }\end{array}$ \\
\hline \multirow{5}{*}{ pep } & \multirow{5}{*}{ paenan } & \multirow{5}{*}{32.8} & $\operatorname{sg} 1$ & pepC & Priming transferase & $2.4 ; 30.4$ \\
\hline & & & $\mathrm{sg} 2$ & pepH & Flippase & $8.9 ; 23.9$ \\
\hline & & & sg3 & $\operatorname{manC}$ & $\begin{array}{l}\text { Mannose-1-phosphate } \\
\text { guanylyltransferase }\end{array}$ & $16.4 ; 16.4$ \\
\hline & & & $\mathrm{sg} 4$ & pepQ & Priming transferase & $24.0 ; 8.8$ \\
\hline & & & sg5 & pepT & Transferase & $30.3 ; 2.5$ \\
\hline \multirow{2}{*}{$d h b$} & \multirow{2}{*}{ bacillibactin } & \multirow{2}{*}{12.4} & sg1 & $d h b E$ & $\begin{array}{l}\text { 2,3-dihydroxybenzoate- } \\
\text { AMP ligase }\end{array}$ & $3.2 ; 9.2$ \\
\hline & & & $\operatorname{sg} 2$ & $d h b F$ & Bacillibactin synthetase & $6.4 ; 6.0$ \\
\hline \multirow{2}{*}{ fus } & \multirow{2}{*}{ fusaricidin } & \multirow{2}{*}{30.7} & $\operatorname{sg} 1$ & fusE & Aldehyde dehydrogenase & $2.9 ; 27.8$ \\
\hline & & & $\mathrm{sg} 2$ & fusA & Fusaricidin synthetase & $20.9 ; 9.8$ \\
\hline \multirow{2}{*}{$p m x$} & \multirow{2}{*}{ polymyxin } & \multirow{2}{*}{41.0} & $\operatorname{sg} 1$ & $p m \times A$ & Polymyxin synthetase A & $2.4 ; 38.6$ \\
\hline & & & $\mathrm{sg} 2$ & $p m x E$ & Polymyxin synthetase E & $22.9 ; 18.1$ \\
\hline
\end{tabular}



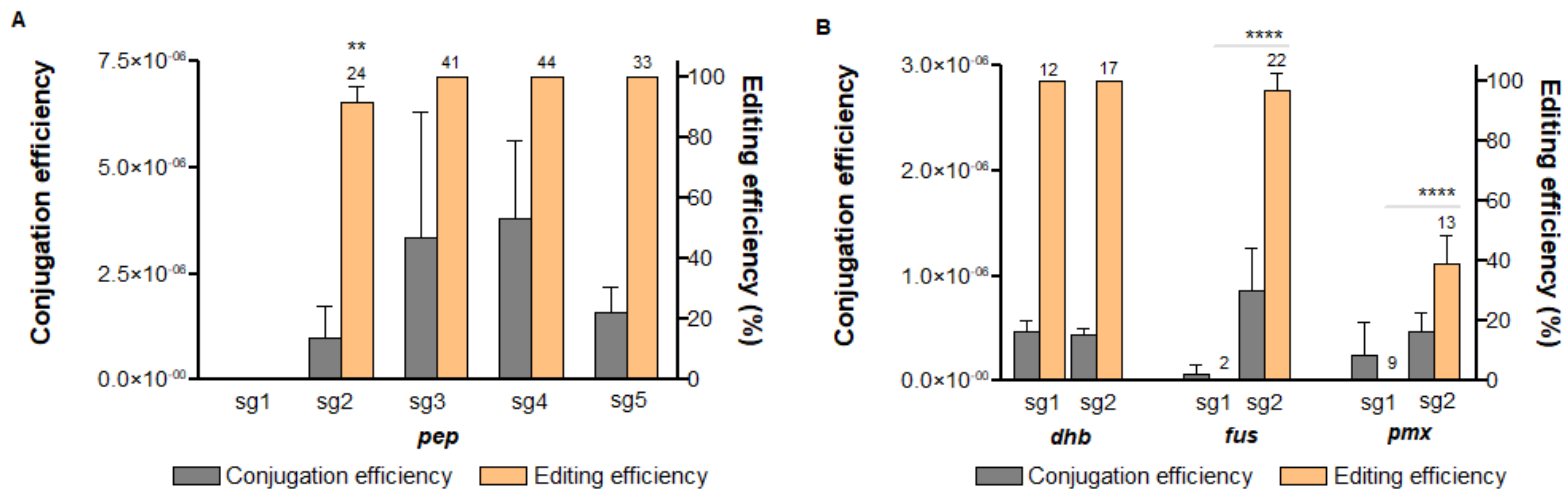

Figure 3. Targeted deletions of different biosynthetic gene clusters of $P$. polymyxa. Five different sites were individually targeted for the pep cluster (A) and two sites each for the $d h b$, fus, and pmx clusters (B). The conjugation efficiency (grey) and editing efficiency (orange) are provided on the Y-axes. The numbers on top of the editing efficiency bar indicate the total number of exconjugants screened. Error bars indicate the standard deviation. $P$ value $<0.05$ was considered in determining the significant differences between the editing efficiencies $\left({ }^{\star *} p<\right.$ $0.01 ; * \star \star \star ~ p<0.0001)$.

Previous studies have demonstrated large cluster deletion in bacteria by the use of CRISPRbased systems. Commonly, dual targeting system with two sgRNAs are used in which the sgRNAs target the start and the end regions of the cluster, what allows a close proximity between the dsDNA break and the homologous regions. ${ }^{12} \mathrm{~A}$ study by So et al. ${ }^{20}$ showed that two sgRNAs were necessary to delete a $38 \mathrm{~kb}$ operon in Bacillus subtilis as utilization of single sgRNA failed in the targeted editing. Studies which describe the use of only one sgRNAguided deletion of large clusters in bacteria are scarce. Recently, it was reported that a chromosomally integrated Cas12a was able to facilitate large cluster deletion in $B$. subtilis by the use of only one sgRNA. ${ }^{21}$ Here, we show highly efficient large cluster deletions with up to $100 \%$ efficiencies by using a one plasmid system with only one sgRNA. We successfully demonstrate targeted deletions of BGCs up to $41 \mathrm{~kb}$. The genome analysis of $P$. polymyxa by the use of antiSMASH ${ }^{22}$ and manual curation suggests that there exist at least 8 BGCs encoding for antimicrobial compounds with sizes ranging from 9 to $58 \mathrm{~kb}$ (Table S6). Therefore, the knowledge obtained in this study will substantially advance the application of Cas9-based approach for genome reduction in $P$. polymyxa, to create a robust production strain with a minimalistic genome.

The ability to perform simultaneous modifications would speed up and simplify the process in creating the strains of interest. Therefore, we were intrigued to exploit further our Cas9-based 
system for multiplexing purposes. Different strategies can be employed to realize the multiplexing, either by using single sgRNA expression cassettes or polycistronic sgRNAs. In the latter case, additional approach is needed to allow the processing of the gRNAs, for example by co-expression of Csy4 or fusing the gRNA with tRNA sequences. ${ }^{23}$ In this study, we applied the former strategy by using single sgRNA expression cassettes in a one plasmid system to allow simple cloning and transformation procedures (Figure 4A). First, we investigated the simultaneous deletion of $p e p C$ and sacB genes, which are essential for two different EPS biosynthesis pathways in P. polymyxa. As discussed above, pepC encodes for an initial glycosyltransferase required for paenan production. On the other hand, sacB encodes for a levansucrase which represents the single enzyme required for biosynthesis of levan, a sucrose-derived fructanosyl polymer. ${ }^{24}$ Disruption of these two genes will lead to a complete loss of EPS production in P. polymyxa.

Typically, conjugation efficiencies of around $1 \times 10^{-4}$ are obtained for single-gene knockouts, although this number seems to vary for different target genes. Single-gene deletions of pepC and sacB were achieved with editing efficiencies of $94 \%$ and $100 \%$, respectively. When aiming for simultaneous deletion of the two genes, the conjugation efficiency dropped significantly by about 70 -fold compared to the single-gene deletions. As expected, deletion of pepC and sacB leads to a non-mucoid growth on EPS glc $_{\text {and }}$ EPS with sucrose as the carbon

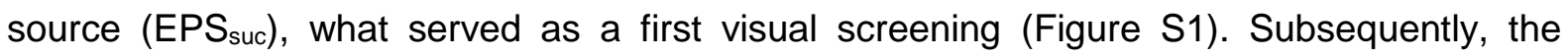
colonies were checked with PCR and sequencing to confirm the desired deletions. The results obtained from PCR and sequencing perfectly matched the visual plate-based screening, what underpins the reliability of the screening method. Despite the decrease in the conjugation efficiency, the editing efficiency of simultaneous gene deletions remained quite high with $85 \%$ (Figure 5A). 

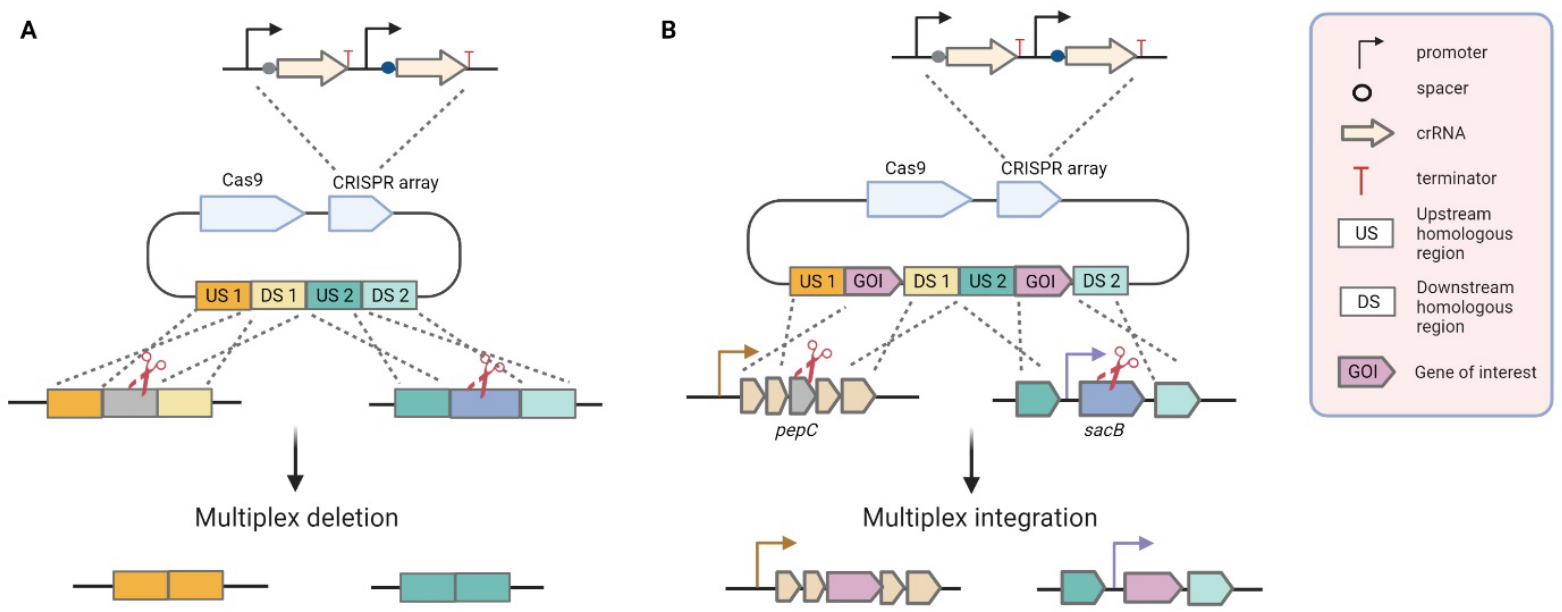

Figure 4. Strategy for Cas9-mediated multiplex genome editing by the use of one plasmid system to achieve two deletions (A) and two integrations (B). The plasmid harbors all elements needed for the targeted modifications including Cas9, CRISPR array, and homologous regions as repair template. The CRISPR array consists of two sgRNA expression cassettes, each of them containing a promoter, spacer sequence, crRNA, and a terminator.

We further investigated whether the system could also be applied to realize multiplex gene integrations (Figure 4B). For this, pepC and $\operatorname{sacB}$ were targeted by using the same sgRNAs cassettes as used for the deletion experiments. In addition, the mRFP gene was placed in between the homologous regions of each targeted gene. Again, the conjugation efficiency decreased by 5 -fold when attempting for multiplex gene integrations in comparison to the multiplex gene deletions. Nevertheless, simultaneous integrations of the mRFP was confirmed with an editing efficiency of $40 \%$ (Figure 5A). Finally, in total 13 colonies were screened, for which 5 colonies showed the correct integration of the $m R F P$ in the targeted positions of pepC and $s a c B$. The other 8 colonies only had the sacB replaced by the $m R F P$ gene while pepC was still intact at the original location. By sequencing the sgRNA cassette of the plasmid from the escapers, mutations in the sgRNA sequence for $p e p C$ were identified, which explained the single targeting of $s a c B$. In these escapers, the sgRNA which was supposed to target the pepC was mutated to the sgRNA sequence targeting the $\operatorname{sacB}$, which suggested that an unwanted recombination happened in the CRISPR array.

Despite the correct integration of the mRFP gene at desired positions in the genome as confirmed by sequencing (Figure S2), it was not functionally expressed. No fluorescence signal was detected in the P. polymyxa mutant, although red coloration was readily visible in the Escherichia coli strains during cloning and conjugation steps. Here, we integrated the 
bioRxiv preprint doi: https://doi.org/10.1101/2021.08.06.455192; this version posted November 8,2021 . The copyright holder for this preprint (which was not certified by peer review) is the author/funder, who has granted bioRxiv a license to display the preprint in perpetuity. It is made available under aCC-BY-NC-ND 4.0 International license.

mRFP gene in place of the pepC and sacB genes, and aimed to achieve its expression by employing the native expression system of $P$. polymyxa, what was not successful in this case. By that, we conducted additional experiments in which we integrated the sfGFP gene, by using similar approach as for the mRFP integration. Multiplex integration of the sfGFP by simultaneously replacing the $p e p C$ and $\operatorname{sacB}$ genes was achieved with an average editing efficiency of $58 \%$ (Figure 5A). Moreover, the sfGPP was successfully expressed, as observed from the visualization by fluorescence microscopy (Figure 5B).

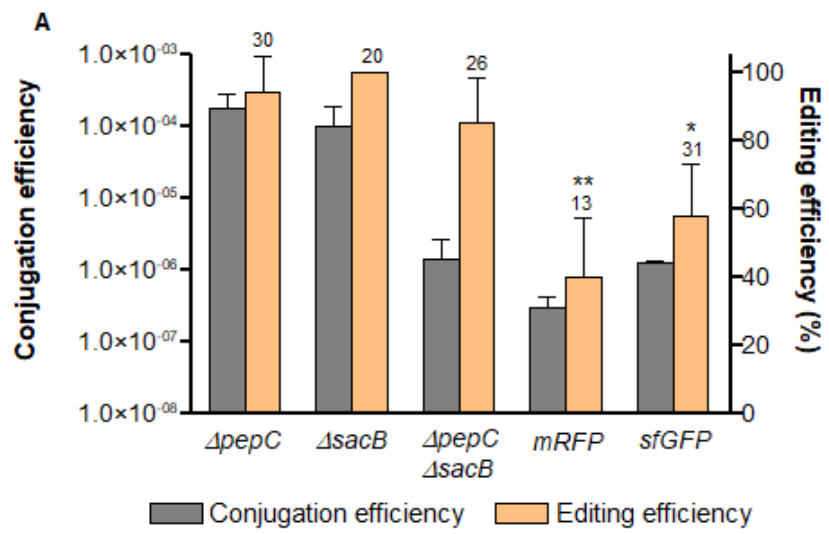

B

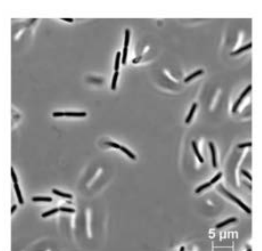

Bright field

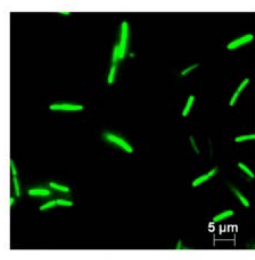

sfGFP

C

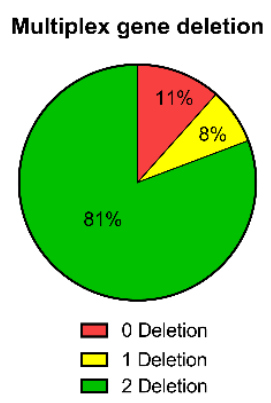

Multiplex gene (mRFP) integration

Multiplex gene (gfp) integration
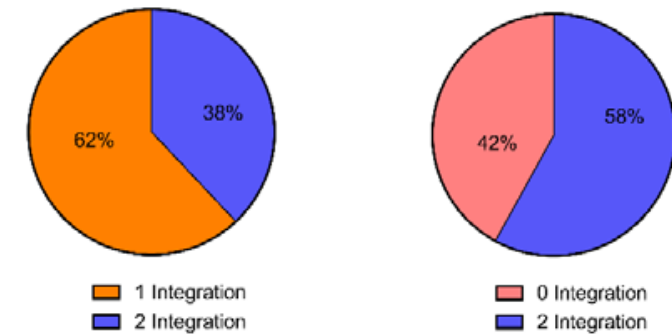

Figure 5. CRISPR-Cas9-based multiplex genome editing for pepC and sacB genes. (A) Conjugation and editing efficiencies of the single gene deletions, multiplex deletions, and multiplex integrations with mRFP or sfGFP as the gene of interest. The conjugation efficiency (grey) and editing efficiency (orange) are provided on the $\mathrm{Y}$-axes. The numbers on top of the editing efficiency bar indicate the total number of exconjugants screened. Error bars indicate the standard deviation. $P$ value $<0.05$ was considered in determining the significant differences between the editing efficiencies $\left({ }^{*} p<0.05 ;{ }^{*} p<0.01\right)$. Significant differences were obtained for multiplex mRFP integrations compared to the single gene deletions as well as multiplex deletions, also for multiplex sfGFP integrations compared to the single gene-deletions. (B) Microscopic images of $P$. polymyxa mutants with sfGFP replacing the pepC and sacB genes. (Left) Bright-field image; (right) GFP channel. (C) The proportion of wild type and mutants obtained from the screening process are provided as pie charts.

The differences in regard of expression of the chromosomally integrated $m R F P$ and $s f G F P$ genes will need further investigations, but can be linked to differences in the necessary promoter and RBS sequences. Furthermore, as the conjugation efficiency obtained from multiplexing approaches was rather low, optimization of transformation procedure might 
improve the efficiency for multiplex integration. ${ }^{25,26}$ Previous studies have reported CRISPRCas-based multiplex genetic engineering in different microorganisms. ${ }^{27-29}$ However, only a few demonstrated multiplex gene integration, which was mainly performed in yeast. ${ }^{30,31}$ While it has been reported in $E$. coli, ${ }^{32}$ to the best of our knowledge, our study is the first to utilize a Cas9-based system to achieve multiplex gene integrations in Gram-positive bacteria.

With the successful results of large cluster deletions and multiplexing, we were intrigued to see whether we could realize multiplexing beyond individual gene levels. Using the similar approach, we aimed to delete the pep and $d h b$ clusters simultaneously. For this purpose, the respective positions of pep-sg4 and $d h b$-sg2 of the pep and $d h b$ clusters were targeted, as described previously. The exconjugants obtained by this approach were then screened based on their mucoid/non-mucoid growth on EPS glc plates, as well as by PCR and sequencing. Remarkably, simultaneous deletion of both clusters could be achieved with an editing efficiency of $83 \%$ (Figure 6), which was comparable to the multiplex deletion of pepC and sacB genes. Among the 21 exconjugants screened, three escapers were identified for which one still had both clusters intact, while the other two had the pep cluster deleted but the $d h b$ cluster intact. As observed for most of the escapers in this study, they were no longer able to grow on selection media containing neomycin, what in consequence hindered the investigation whether there was any mutation in the sgRNAs. We hypothesize that, in this case, mutations in the origin of replication on the Cas9-encoding plasmid might have occurred, as described by Uribe et al. ${ }^{33}$
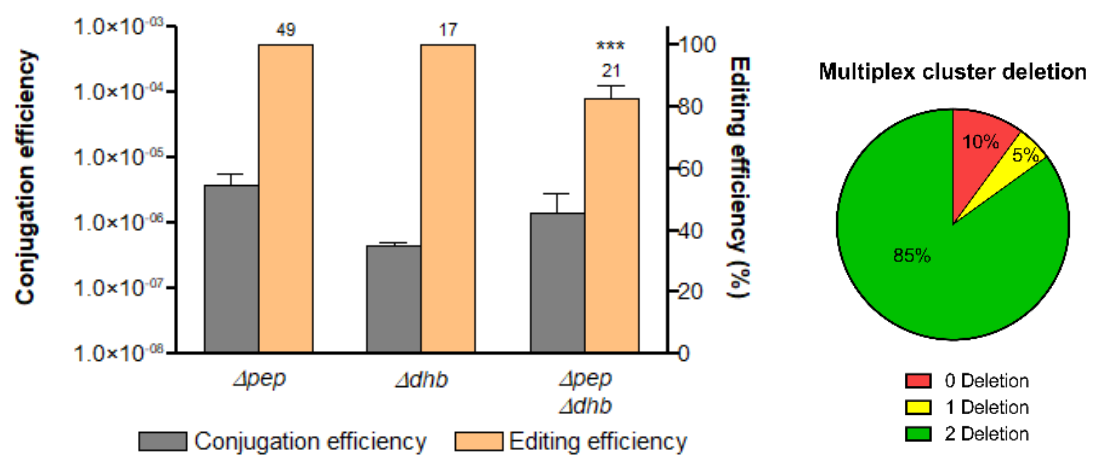

Figure 6. CRISPR-Cas9-based multiplex genome editing for pep and $d h b$ clusters (B). The conjugation efficiency (grey) and editing efficiency (orange) are provided on the $\mathrm{Y}$-axes. The numbers on top of the editing efficiency bar indicate the total number of exconjugants screened. Error bars indicate the standard deviation. $P$ value $<0.05$ was 
considered in determining the significant differences between the editing efficiencies ( ${ }^{\star \star \star} p<0.001$ ). The proportion of wild type and mutants obtained from the screening process are also provided as a pie chart.

To summarize, in this study, we demonstrate the utilization of our Cas9-based system for multiple purposes in P. polymyxa. In addition to single-gene deletions, we show that the system has high efficiencies for large cluster deletions as well as multiplex genome editing on gene and gene-cluster levels. Especially, we want to highlight the findings of the influence of the different targeting sgRNAs for different BGCs, in which it becomes obvious that targeting a region in the middle or closer to the $3^{\prime}$ end is more beneficial for large cluster deletion. The approach of multiplex cluster deletion allowed us to simultaneously delete two distantly located BGCs, which in total reduced $45 \mathrm{~kb}$ of the $P$. polymyxa genome. By that, we could show that this is a powerful approach for genome reduction towards specific minimalistic chassis variants. As a proof of principle, we also demonstrate multiplex gene integrations, which is rarely described in bacteria. Thus, the knowledge obtained in this study is expected to be substantial in strain development, especially when aiming for iterative genome editing. Multiplex integrations to simultaneously replace different BGCs would be an attractive direction to look into, but optimization of transformation efficiency is needed for this purpose. Finally, we anticipate a wider utilization of our Cas9-based system for future research in $P$. polymyxa and related species.

\section{Methods}

\section{Strains and cultivation}

P. polymyxa DSM 365 was obtained from the German Collection of Microorganisms and Cell Culture (DSMZ, Germany). E. coli Turbo (New England Biolabs) or E. coli Top10 (Invitrogen) was used for plasmid cloning and storage. E. coli S17-1 (ATCC 47055) was used to facilitate the conjugation of $P$. polymyxa. The strains were cultivated in LB media ( $10 \mathrm{~g} / \mathrm{L}$ peptone, 5 $\mathrm{g} / \mathrm{L}$ yeast extract, $5 \mathrm{~g} / \mathrm{L} \mathrm{NaCl}$ ). For plate media, $1.5 \%$ agar was added. If necessary, the media was supplemented with $50 \mu \mathrm{g} / \mathrm{mL}$ neomycin and/or $40 \mu \mathrm{g} / \mathrm{mL}$ polymyxin. $P$. polymyxa was cultivated at $30^{\circ} \mathrm{C}$ and $\mathrm{E}$. coli strains at $37^{\circ} \mathrm{C}$, unless stated otherwise. Liquid cultures were prepared in $3 \mathrm{~mL}$ media in $13 \mathrm{~mL}$ tubes and incubated at $250 \mathrm{rpm}$. To check for EPS formation, 
P. polymyxa was grown on EPS-inducing plates containing $30 \mathrm{~g} / \mathrm{L}$ glucose or $30 \mathrm{~g} / \mathrm{L}$ sucrose, $5 \mathrm{~g} / \mathrm{L}$ peptone, $1.33 \mathrm{~g} / \mathrm{L} \mathrm{MgSO}_{4} .7 \mathrm{H}_{2} \mathrm{O}, 0.05 \mathrm{~g} / \mathrm{L} \mathrm{CaCl}, 1.67 \mathrm{~g} / \mathrm{L} \mathrm{KH}_{2} \mathrm{PO}_{4}, 2 \mathrm{~mL} / \mathrm{L}$ RPMI 1640 vitamin solution (Sigma-Aldrich), and $1 \mathrm{~mL} / \mathrm{L}$ trace elements $\left(2.5 \mathrm{~g} / \mathrm{L} \mathrm{FeSO} 4.7 \mathrm{H}_{2} \mathrm{O}, 2.1 \mathrm{~g} / \mathrm{L}\right.$ $\mathrm{C}_{4} \mathrm{H}_{4} \mathrm{Na}_{2} \mathrm{O}_{6} .2 \mathrm{H}_{2} \mathrm{O}, 1.8 \mathrm{~g} / \mathrm{L} \mathrm{MnCl}{ }_{2} .4 \mathrm{H}_{2} \mathrm{O}, 0.075 \mathrm{~g} / \mathrm{L} \mathrm{CoCl} 2.6 \mathrm{H}_{2} \mathrm{O}, 0.031 \mathrm{~g} / \mathrm{L} \mathrm{CuSO}{ }_{4} .7 \mathrm{H}_{2} \mathrm{O}, 0.258$ $\left.\mathrm{g} / \mathrm{L} \mathrm{H}_{3} \mathrm{BO}_{3}, 0.023 \mathrm{~g} / \mathrm{L} \mathrm{Na}_{2} \mathrm{MoO}_{4}, 0.021 \mathrm{~g} / \mathrm{L} \mathrm{ZnCl} 2\right) .{ }^{14}$ For longer storage, the strains were stored in $24 \%$ glycerol and kept at $-80^{\circ} \mathrm{C}$. All strains used in this study are listed in Table S1.

\section{Plasmid construction}

All fragments for cloning purposes were amplified by the use of Accuzyme polymerase (Bioline). Gel purification was performed by using the Monarch Gel Purification Kit (NEB). Isolation of genomic DNA (gDNA) was performed with the DNeasy Blood \& Tissue Kit (Qiagen). The pCasPP plasmid was used as vector for the different experiments in this study. ${ }^{14}$ The plasmid itself is $9.7 \mathrm{~kb}$ in size, containing Cas9 of $S$. pyogenes which was codon optimized for Streptomyces as well as sgRNA expression cassette. ${ }^{18}$ In addition, pCasPP also has the elements which support its replication in E. coli and P. polymyxa as well as origin of transfer for conjugation purpose. All the plasmids were assembled by isothermal assembly. Linear fragments were obtained from PCR amplifications using primers with suitable overlapping sequences. The spacer sequences were identified within the targeted genes and located directly upstream of the NGG PAM sites. In this study, 20-nt spacer sequences were used. Approximately $1 \mathrm{~kb}$ homologous regions upstream and downstream of the targeted regions were amplified from $P$. polymyxa gDNA and provided as repair template for the HDR. For multiplex integrations experiment, the mRFP was amplified from the pLux01 plasmid, which was a gift from Tom Ellis (Addgene plasmid \#78281), ${ }^{34}$ and placed in between the homologous regions. Finally, all fragments were mixed together in the isothermal assembly master mix and incubated at $50{ }^{\circ} \mathrm{C}$ for 1 hour followed by transformation of E. coli Turbo or E. coli Top10 via heat shock method. Transformed cells were plated on LB agar containing $50 \mu \mathrm{g} / \mathrm{mL}$ of neomycin. The transformants were initially screened with colony PCR using GoTaq polymerase (Promega) then plasmid isolation was performed by using GeneJET Plasmid 
bioRxiv preprint doi: https://doi.org/10.1101/2021.08 .06.455192; this version posted November 8, 2021. The copyright holder for this preprint (which was not certified by peer review) is the author/funder, who has granted bioRxiv a license to display the preprint in perpetuity. It is made available under aCC-BY-NC-ND 4.0 International license.

Miniprep Kit (Thermo Fisher Scientific). Subsequently, the plasmid was checked by sequencing to confirm that the correct plasmid was assembled. Upon confirmation, E. coli S17-1 was transformed with the plasmid, also by using heat shock method. All primers synthesis and sequencing analysis were performed by Microsynth AG (Switzerland). In silico primer design, cloning, and sequence alignment were performed by using SnapGene version 5.1.5. The spacer sequences were selected based on their respective positions in the targeted regions as well as high on-target scores as analyzed by Benchling platform. The figures were created by using BioRender. The plasmids, oligonucleotides, and spacer sequences used in this study are listed in Table S1-S3. Detailed information of the materials used in this study is provided in Table S4.

\section{Conjugation}

P. polymyxa transformation was performed via conjugation by the use of E. coli S17-1 as donor strain. Single colonies of the strains were inoculated in $3 \mathrm{~mL}$ LB media, with or without $50 \mu \mathrm{g} / \mathrm{mL}$ of neomycin, and cultivated overnight. The overnight culture was diluted 1:100 in fresh media then cultivated for $4 \mathrm{~h}$ at $37^{\circ} \mathrm{C}$ and $250 \mathrm{rpm}$. Subsequently, $900 \mu \mathrm{L}$ of $P$. polymyxa culture was incubated at $42{ }^{\circ} \mathrm{C}$ for 15 min then mixed with $300 \mu$ of the $E$. coli S17-1 harboring the plasmid of interest. The mixture was centrifuged at $8,000 \mathrm{rpm}$ for $3 \mathrm{~min}$ then the pellet was resuspended in $100 \mu \mathrm{L}$ of LB media. The solution was dropped on an LB plate and incubated overnight at $30^{\circ} \mathrm{C}$. Afterwards, the culture was scrapped off the plate and resuspended in 150 $\mu \mathrm{L}$ of $\mathrm{LB}$ media, Subsequently, the culture was plated on LB plates containing $50 \mu \mathrm{g} / \mathrm{mL}$ of neomycin and $40 \mu \mathrm{g} / \mathrm{mL}$ of polymyxin, followed by incubation for $48 \mathrm{~h}$ at $30{ }^{\circ} \mathrm{C}$. If necessary, plating with serial dilutions was performed to obtain countable colonies on the plates. All experiments were performed in three biological replicates. Conjugation efficiency was calculated as the total number of exconjugants per viable recipient cells. Editing efficiency was calculated from the number of correct mutants divided by total number of exconjugants screened from each conjugation round. The numbers of exconjugants as well as conjugation and editing efficiencies obtained from the different experiments are provided in Table S5. 


\section{Screening of $P$. polymyxa exconjugants}

Screening of the exconjugants was mainly performed by PCR and sequencing. In addition, the plate-based assays were also used to screen for mutants whose EPS-related genes or cluster were deleted. For this, the colonies were streaked on EPS-inducing plates to check for the loss of slimy phenotype which indicated the elimination of EPS formation. An EPS glc plate was used for initial screening of the pepC gene or pep cluster knockout. In addition, an EPS suc $_{\text {s }}$ plate was used to screen for the $\Delta s a c B \Delta p e p C$ double knockout mutants. The colonies were incubated at $30{ }^{\circ} \mathrm{C}$ overnight. Subsequently, the colonies were checked via colony PCR to verify the accuracy of the plate-based assay. Colony PCR was performed using primers which bind outside of the homologous regions provided as repair template. The resulting fragment was purified from the gel and sent for sequencing to confirm the modifications. Finally, gDNA was isolated from some of the colonies and again checked with PCR and sequencing to reconfirm the colony PCR results. Analysis with fluorescence microscopy was performed by using Carl Zeiss HBO 100 microscope. Microscopic images were processed with AxioVision imaging software.

\section{Statistical analysis}

Statistical analysis was performed using GraphPad Prism version 7. Editing efficiencies of different experiments with the same scope were compared using One-Way ANOVA with Tukey correction. $\mathrm{P}$ value $<0.05$ was considered significant.

\section{Associated Content}

Supporting Information

\section{Author Information}

\section{Corresponding author}

^E-mail: jochen.schmid@uni-muenster.de. 
bioRxiv preprint doi: https://doi.org/10.1101/2021.08.06.455192; this version posted November $8,2021$. The copyright holder for this preprint (which was not certified by peer review) is the author/funder, who has granted bioRxiv a license to display the preprint in perpetuity. It is made available under aCC-BY-NC-ND 4.0 International license.

\section{Author Contributions}

$\mathrm{MM}$ and JS designed the experiments and wrote the manuscript. MM and CT performed the experiments and analyzed the data. All authors read and approved the final manuscript.

\section{Notes}

The authors declare no competing financial interests.

\section{Acknowledgements}

This study is part of the German Federal Ministry of Education and Research (BMBF) funded project Polymore with the number 031B0855A.

\section{References}

(1) Jeong, H.; Choi, S. K.; Ryu, C. M.; Park, S. H. Chronicle of a Soil Bacterium: Paenibacillus polymyxa E681 as a Tiny Guardian of Plant and Human Health. Front. Microbiol. 2019, 10 (MAR), 1-16. https://doi.org/10.3389/fmicb.2019.00467.

(2) Rütering, M.; Schmid, J.; Rühmann, B.; Schilling, M.; Sieber, V. Controlled Production of Polysaccharides-Exploiting Nutrient Supply for Levan and Heteropolysaccharide Formation in Paenibacillus Sp. Carbohydr. Polym. 2016, 148, 326-334. https://doi.org/10.1016/j.carbpol.2016.04.074.

(3) Blombach, B.; Grünberger, A.; Centler, F.; Wierckx, N.; Schmid, J. Exploiting Unconventional Prokaryotic Hosts for Industrial Biotechnology. Trends Biotechnol. 2021, 1-13. https://doi.org/10.1016/j.tibtech.2021.08.003.

(4) Choi, S. K.; Park, S. Y.; Kim, R.; Lee, C. H.; Kim, J. F.; Park, S. H. Identification and Functional Analysis of the Fusaricidin Biosynthetic Gene of Paenibacillus polymyxa E681. Biochem. Biophys. Res. Commun. 2008, 365 (1), 89-95. https://doi.org/10.1016/j.bbrc.2007.10.147.

(5) Zarschler, K.; Janesch, B.; Zayni, S.; Schaffer, C.; Messner, P. Construction of a Gene Knockout System for Application in Paenibacillus alvei CCM 2051T, Exemplified by the S-Layer Glycan Biosynthesis Initiation Enzyme WsfP. Appl. Environ. Microbiol. 2009, 75 (10), 3077-3085. https://doi.org/10.1128/AEM.00087-09.

(6) Kim, S. Bin; Timmusk, S. A Simplified Method for Gene Knockout and Direct Screening of Recombinant Clones for Application in Paenibacillus polymyxa. PLoS One 2013, 8 (6). https://doi.org/10.1371/journal.pone.0068092.

(7) Jinek, M.; Chylinski, K.; Fonfara, I.; Hauer, M.; Doudna, J. A.; Charpentier, E. A Programmable DualRNA-Guided DNA Endonuclease in Adaptive Bacterial Immunity. Science (80-. ). 2012, 337 (6096), 816821. https://doi.org/10.1126/science.1225829.

(8) Makarova, K. S.; Wolf, Y. I.; Iranzo, J.; Shmakov, S. A.; Alkhnbashi, O. S.; Brouns, S. J. J.; Charpentier, E.; Cheng, D.; Haft, D. H.; Horvath, P.; Moineau, S.; Mojica, F. J. M.; Scott, D.; Shah, S. A.; Siksnys, V.; Terns, M. P.; Venclovas, Č.; White, M. F.; Yakunin, A. F.; Yan, W.; Zhang, F.; Garrett, R. A.; Backofen, R.; van der Oost, J.; Barrangou, R.; Koonin, E. V. Evolutionary Classification of CRISPR-Cas Systems: A Burst of Class 2 and Derived Variants. Nat. Rev. Microbiol. 2020, 18 (2), 67-83. https://doi.org/10.1038/s41579-019-0299-x.

(9) Szostak, J. W.; Orr-Weaver, T. L.; Rothstein, R. J.; Stahl, F. W. The Double-Strand-Break Repair Model for Recombination. Cell 1983, 33 (1), 25-35. https://doi.org/10.1016/0092-8674(83)90331-8.

(10) Chayot, R.; Montagne, B.; Mazel, D.; Ricchetti, M. An End-Joining Repair Mechanism in Escherichia Coli. Proc. Natl. Acad. Sci. U. S. A. 2010, 107 (5), 2141-2146. https://doi.org/10.1073/pnas.0906355107.

(11) Lieber, M. R. The Mechanism of DSB Repair by the NHEJ. Annu. Rev. Biochem. 2011, 79 (3), $181-211$. https://doi.org/10.1146/annurev.biochem.052308.093131.

(12) Standage-Beier, K.; Zhang, Q.; Wang, X. Targeted Large-Scale Deletion of Bacterial Genomes Using CRISPR-Nickases. ACS Synth. Biol. 2015, 4 (11), 1217-1225.

https://doi.org/10.1021/acssynbio.5b00132. 
bioRxiv preprint doi: https://doi.org/10.1101/2021.08.06.455192; this version posted November 8,2021 . The copyright holder for this preprint (which was not certified by peer review) is the author/funder, who has granted bioRxiv a license to display the preprint in perpetuity. It is made available under aCC-BY-NC-ND 4.0 International license.

(13) Schilling, C.; Koffas, M. A. G.; Sieber, V.; Schmid, J. Novel Prokaryotic CRISPR-Cas12a-Based Tool for Programmable Transcriptional Activation and Repression. ACS Synth. Biol. 2021, 9 (12), 3353-3363. https://doi.org/10.1021/acssynbio.0c00424.

(14) Rütering, M.; Cress, B. F.; Schilling, M.; Rühmann, B.; Koffas, M. A. G.; Sieber, V.; Schmid, J. TailorMade Exopolysaccharides-CRISPR-Cas9 Mediated Genome Editing in Paenibacillus polymyxa. Synth. Biol. 2017, 2 (1), 1-12. https://doi.org/10.1093/synbio/ysx007.

(15) Kim, M. S.; Kim, H. R.; Jeong, D. E.; Choi, S. K. Cytosine Base Editor-Mediated Multiplex Genome Editing to Accelerate Discovery of Novel Antibiotics in Bacillus subtilis and Paenibacillus polymyxa. Front. Microbiol. 2021, 12 (May). https://doi.org/10.3389/fmicb.2021.691839.

(16) Chi, H.; Wang, X.; Shao, Y.; Qin, Y.; Deng, Z.; Wang, L.; Chen, S. Engineering and Modification of Microbial Chassis for Systems and Synthetic Biology. Synth. Syst. Biotechnol. 2019, 4 (1), 25-33. https://doi.org/10.1016/j.synbio.2018.12.001.

(17) Calero, P.; Nikel, P. I. Chasing Bacterial Chassis for Metabolic Engineering: A Perspective Review from Classical to Non-Traditional Microorganisms. Microb. Biotechnol. 2019, 12 (1), 98-124. https://doi.org/10.1111/1751-7915.13292.

(18) Cobb, R. E.; Wang, Y.; Zhao, H. High-Efficiency Multiplex Genome Editing of Streptomyces Species Using an Engineered CRISPR/Cas System. ACS Synth. Biol. 2015, 4 (6), 723-728. https://doi.org/10.1021/sb500351f.

(19) Schilling, C.; Ciccone, R.; Sieber, V.; Schmid, J. Engineering of the 2,3-Butanediol Pathway of Paenibacillus polymyxa DSM 365. Metab. Eng. 2020, 61 (June), 381-388. https://doi.org/10.1016/j.ymben.2020.07.009.

(20) So, Y.; Park, S. Y.; Park, E. H.; Park, S. H.; Kim, E. J.; Pan, J. G.; Choi, S. K. A Highly Efficient CRISPRCas9-Mediated Large Genomic Deletion in Bacillus subtilis. Front. Microbiol. 2017, 8 (JUN), 1-12. https://doi.org/10.3389/fmicb.2017.01167.

(21) Hao, W.; Suo, F.; Lin, Q.; Chen, Q.; Zhou, L.; Liu, Z.; Cui, W.; Zhou, Z. Design and Construction of Portable CRISPR-Cpf1-Mediated Genome Editing in Bacillus subtilis 168 Oriented Toward Multiple Utilities. Front. Bioeng. Biotechnol. 2020, 8 (September), 1-14. https://doi.org/10.3389/fbioe.2020.524676.

(22) Blin, K.; Shaw, S.; Kloosterman, A. M.; Charlop-Powers, Z.; Van Wezel, G. P.; Medema, M. H.; Weber, T. AntiSMASH 6.0: Improving Cluster Detection and Comparison Capabilities. Nucleic Acids Res. 2021, 49 (W1), W29-W35. https://doi.org/10.1093/nar/gkab335.

(23) Adiego-Pérez, B.; Randazzo, P.; Daran, J. M.; Verwaal, R.; Roubos, J. A.; Daran-Lapujade, P.; Van Der Oost, J. Multiplex Genome Editing of Microorganisms Using CRISPR-Cas. FEMS Microbiol. Lett. 2019, 366 (8), 1-19. https://doi.org/10.1093/femsle/fnz086.

(24) Schmid, J.; Sieber, V.; Rehm, B. Bacterial Exopolysaccharides: Biosynthesis Pathways and Engineering Strategies. Front. Microbiol. 2015, 6 (MAY), 1-24. https://doi.org/10.3389/fmicb.2015.00496.

(25) Brito, L. F.; Irla, M.; Walter, T.; Wendisch, V. F. Magnesium Aminoclay-Based Transformation of Paenibacillus riograndensis and Paenibacillus polymyxa and Development of Tools for Gene Expression. Appl. Microbiol. Biotechnol. 2017, 101 (2), 735-747. https://doi.org/10.1007/s00253-016-7999-1.

(26) Liu, D.; Huang, C.; Guo, J.; Zhang, P.; Chen, T.; Wang, Z.; Zhao, X. Development and Characterization of a CRISPR/Cas9n-Based Multiplex Genome Editing System for Bacillus subtilis. Biotechnol. Biofuels 2019, 12 (1), 1-17. https://doi.org/10.1186/s13068-019-1537-1.

(27) Ferreira, R.; Skrekas, C.; Nielsen, J.; David, F. Multiplexed CRISPR/Cas9 Genome Editing and Gene Regulation Using Csy4 in Saccharomyces cerevisiae. ACS Synth. Biol. 2018, 7 (1), 10-15. https://doi.org/10.1021/acssynbio.7b00259.

(28) Meliawati, M.; Schilling, C.; Schmid, J. Recent Advances of Cas12a Applications in Bacteria. Appl. Microbiol. Biotechnol. 2021. https://doi.org/10.1007/s00253-021-11243-9.

(29) Ronda, C.; Pedersen, L. E.; Sommer, M. O. A.; Nielsen, A. T. CRMAGE: CRISPR Optimized MAGE Recombineering. Sci. Rep. 2016, 6 (December 2015), 1-11. https://doi.org/10.1038/srep19452.

(30) Verwaal, R.; Buiting-Wiessenhaan, N.; Dalhuijsen, S.; Roubos, J. A. CRISPR/Cpf1 Enables Fast and Simple Genome Editing of Saccharomyces cerevisiae. Yeast 2018, 35 (2), 201-211. https://doi.org/10.1002/yea.3278.

(31) Li, Z. H.; Wang, F. Q.; Wei, D. Z. Self-Cloning CRISPR/Cpf1 Facilitated Genome Editing in 
bioRxiv preprint doi: https://doi.org/10.1101/2021.08.06.455192; this version posted November 8,2021 . The copyright holder for this preprint (which was not certified by peer review) is the author/funder, who has granted bioRxiv a license to display the preprint in perpetuity. It is made available under aCC-BY-NC-ND 4.0 International license.

Saccharomyces cerevisiae. Bioresour. Bioprocess. 2018, 5 (1), 1-12. https://doi.org/10.1186/s40643018-0222-8.

(32) Ao, X.; Yao, Y.; Li, T.; Yang, T. T.; Dong, X.; Zheng, Z. T.; Chen, G. Q.; Wu, Q.; Guo, Y. A Multiplex Genome Editing Method for Escherichia coli Based on CRISPR-Cas12a. Front. Microbiol. 2018, 9 (OCT), 1-13. https://doi.org/10.3389/fmicb.2018.02307.

(33) Uribe, R. V.; Rathmer, C.; Jahn, L. J.; Ellabaan, M. M. H.; Li, S. S.; Sommer, M. O. A. Bacterial Resistance to CRISPR-Cas Antimicrobials. Sci. Rep. 2021, 11 (1), 1-9. https://doi.org/10.1038/s41598021-96735-4.

(34) Florea, M.; Hagemann, H.; Santosa, G.; Abbott, J.; Micklem, C. N.; Spencer-Milnes, X.; de Arroyo Garcia, L.; Paschou, D.; Lazenbatt, C.; Kong, D.; Chughtai, H.; Jensen, K.; Freemont, P. S.; Kitney, R.; Reeve, B.; Ellis, T. Engineering Control of Bacterial Cellulose Production Using a Genetic Toolkit and a New Cellulose-Producing Strain. Proc. Natl. Acad. Sci. 2016, 113 (24), E3431-E3440. https://doi.org/10.1073/pnas.1522985113. 